\title{
Professional Competence of Translator Trainees in China
}

\author{
Li GAO ${ }^{1, a}$, Hai-Tang REN ${ }^{1, b}$ and Xue-Li TONG ${ }^{2, c,}$, \\ ${ }^{1}$ College of Foreign Languages, Northwest University, Shaanxi, China \\ ${ }^{2}$ School of Marxism, Northwest University, Shaanxi, China \\ aligao@nwu.edu.cn, ${ }^{b}$ rhait@126.com, ${ }^{c}$ tongxueli@nwu.edu.cn \\ ${ }^{*}$ Corresponding author
}

Keywords: Professional competence, MTI students, Professional knowledge.

\begin{abstract}
Global economy has brought greater need for translators in China. The creation of MTI (Master of Translation and Interpreting) programs is to prepare more professional translators. This makes it necessary to examine the status quo of the professional competence (PC) of MTI students. The study surveyed 844 student translators of seven MTI programs and found that their current state of PC was slightly above the average, and their amount of professional knowledge is far from sufficient though their professional attitudes were satisfactory.
\end{abstract}

\section{Introduction}

Last decade witnessed the rapid development of translator education in China and over two hundred MTI programs have been accredited to train translators. However, recent research has revealed that a large number of graduates did not work as translators [1]. Also various issues have existed in the current programs [2]. Previous research has investigated the professional preparation environment of translator training and it revealed that social environment was quite worrisome [3] and an analysis of the outcome of MTI program, i.e. professional competence of student translators will help translator education in China.

\section{Conceptual Framework}

Recent literature reveals that the issue of the competence of professional and student translators has been much discussed. Considerable attention has been put on the differences between translation competence and translator competence. Now the pendulum has come back to the latter. The professional competence of MTI students is of more interest to the researchers.

Though the concept of competence originated from [4] in 1970s and has been explored in quite a few professional fields, the status quo of professional competence of Chinese student translator remains unknown. Before a survey is conducted to explore their perceptions of their PC a brief review of its components is necessary.

The components of competence have been much researched. [5] categorized it into professional skill and professional attitude after testing it with a few professional programs. A similar research has been conducted to design curriculum for nurses working in disaster areas [6]. As to the competence required for translators an empirical study of professional translators unveiled that it consisted of knowledge, skills, ethics, values etc [7]. Also researchers tackled the issue from the perspective of employers and stated that professional translators should have the knowledge of particular field, the skill of translation and know how to research, edit, communicate and manage the files [8]. These all contribute to the design of PC scale for MTI students.

Based on precious researches this study is interested in investigating the status quo of PC of MTI students in Chinese higher education institutions. A collection of professional knowledge (PK), professional skills (PS) and professional attitudes (PA) has been compiled. The first includes the knowledge of special fields, technical terms and translation; the second consists of the skills of intercultural communication, proficiency of English and Chinese; the last is concerned with professional beliefs, ethnics, conduct and professional development. 


\section{Research Design}

Four main research paradigms exist in educational research, which are scientific and positivistic research, naturalistic and interpretative research, research based on critical theory and feminist education research. The study is to verify the existence of PC, understand its components, investigate its status quo and compare the differences in perception between different groups of MTI students and institutions, and the scientific and positivistic paradigm fits our research purposes better and an empirical experiment was conducted accordingly.

\section{Research Questions}

To serve the purposes of the research two research questions are to be probed: 1 . What is the status quo of the PC of MTI students in China? 2. Are there any statistically significant differences in the perceptions of PC between different groups of students and institutions?

\section{Population and Sample Size}

The identification and the size of the survey is a critical issue to consider and factors like expense, time and accessibility often prevent researchers from gaining information from the whole population. While it may not be realistic to survey all the MTI programs (215 in total), there is also no need to do so. A quick look at the programs shows that about one fourth do not have recruits until the autumn of 2015, and the rest can be put into two groups. One group, the majority of programs, offers two-year MTI programs and the other runs either two-and-a-half-year or three-year programs. Taking into account that the year of program plays an important part in the PC and would influence the perception of students accordingly, we chose to focus on those MTI programs whose year of program is over two years, i.e. the programs that have the first-, second- and third- year students. This filters the population to a sample of seven institutions. Of them three are located in west China and they are Northwest University, Guizhou University and Xi' an International Studies University. Four are in east China and they are Shandong University, Nanjing University, Tianjin Foreign Studies University and Shanghai International Studies University. All the MTI students of the seven institutions were surveyed between late September and mid-October of 2014.

\section{Survey Instrument}

A questionnaire was designed to incorporate the factors influencing the PC of MTI programs. It consists of two sections. Section One is a profile of survey respondents and has 12 items and they are all multiple-choice questions. Section Two collects the perception of the PC of MTI students and contains 26 items. This section asks students to evaluate specific aspect of PC they have acquired. The part of PK comprises four items (s1-s4), PS has 13 items (s5-s17) and PA nine items (s18-s26). The scale is of the Likert-type with $1=$ completely disagree and $5=$ completely agree. Stratified sampling was used to collect data.

\section{Data Collection and Analysis}

The administration of the questionnaire was conducted between late September and mid-October of 2014. Printed and electronic copies of questionnaires as well as cover letter explaining the purposes and the procedure of implementing the study were posted to the respective contact person of seven MTI programs. These contact people were either full-time teachers or administrators of MTI programs and have access to MTI students and are in a position to help bring a higher return rate of questionnaires. 844 questionnaires were sent and within two weeks (the recommended time) 685 questionnaires were returned, of which 602 ones had complete information and were analyzed. The returned rate was $71.3 \%$ and the distribution of the questionnaires and the characteristics of the respondents are in Table 1 and Table 2 respectively. 
Table 1 Distribution of questionnaires

\begin{tabular}{lccccccc}
\hline \multirow{2}{*}{ Region } & \multirow{2}{*}{ Institution } & \multicolumn{2}{c}{ Printed Copies } & \multicolumn{2}{c}{ Electronic Copies } & Returned Copies & \multirow{2}{*}{ Percentage } \\
\cline { 2 - 7 } & Sent & Returned & Sent & Returned & Total & \\
\hline West & $\mathrm{A}$ & 103 & 89 & 47 & 29 & 118 & $17.1 \%$ \\
China & $\mathrm{B}$ & 144 & 117 & 77 & 25 & 142 & $21 \%$ \\
& $\mathrm{C}$ & 41 & 39 & 18 & 12 & 51 & $7.4 \%$ \\
East & $\mathrm{D}$ & 72 & 62 & 0 & 0 & 62 & $9 \%$ \\
China & $\mathrm{E}$ & 80 & 62 & 0 & 0 & 62 & $9 \%$ \\
& $\mathrm{~F}$ & 94 & 93 & 5 & 2 & 95 & $13.9 \%$ \\
& $\mathrm{G}$ & 122 & 116 & 41 & 39 & 155 & $22.6 \%$ \\
\hline
\end{tabular}

Table 2 Information of the respondents

\begin{tabular}{llllllll}
\hline \multicolumn{1}{c}{ Variable } & \multicolumn{1}{c}{ Group } & Sample & $\%$ & \multicolumn{1}{c}{ Variable } & \multicolumn{1}{c}{ Group } & sample & $\%$ \\
\hline Gender & Female & 506 & 84.1 & English & CET4 & 2 & .3 \\
& Male & 96 & 15.9 & Proficiency & CET6 & 63 & 10.5 \\
Grade of & Year One & 278 & 46.2 & & TEM4 & 17 & 2.8 \\
Respondents & Year Two & 217 & 36.0 & & TEM8 & 520 & 86.4 \\
& Year Three & 107 & 17.8 & Type of & Comprehensive & 275 & 45.7 \\
Part-time & No & 471 & 78.2 & University & Foreign Studies & 327 & 54.3 \\
& Yes & 131 & 21.8 & Location of & West China & 270 & 44.9 \\
\multirow{2}{*}{ HEI of First } & Ordinary & 421 & 69.9 & University & East China & 332 & 55.1 \\
Degree & Project 211 & 120 & 19.9 & Major of BA & Non-Englsih & 74 & 12.3 \\
& Project 985 & 61 & 10.1 & & English & 528 & 87.7 \\
\hline
\end{tabular}

Software packages SPSS and AMOS were used to analyze the collected data and methods like descriptive statistics, item analysis, exploratory factor analysis and confirmatory factor analysis were applied where necessary.

\section{Findings}

\section{Reliability and Validity of Instrument}

The study was based on the conceptual framework of [4] and [5] and the items of the questionnaire were designed accordingly. To test the reliability and validity of the questionnaire, the collected data was randomly equally split into two groups and each had 301 cases. One group was used for exploratory factor analysis and the other for confirmatory factory analysis.

Before conducting exploratory factor analysis, item analysis was first conducted to exclude particular items that were not congruent with others and this contributes to the improvement of the reliability of items. Critical ration method was used and all items were therefore kept. Then Cronbach Alpha, which provides a coefficient of inter-item correlations and is a measure of internal consistency among the items, was calculated to find out how reliable it is for data collection. It found out Cronbach Alpha of the PC scale is 0.89 and it is acceptable at 0.8 .

Two parallel factor analyses that included 26 influence variables were then conducted. The first analysis was conducted on 301 cases which were randomly selected from the sample and the second analysis was conducted using the other half remaining sample. The results were essentially identical. These analyses consistently resulted in four factors with eigenvalues grater than 1.0 and the four factors accounted for $61.089 \%$ percent of variance (see Table 3). It finds that the first factor is composed of the knowledge of technical terms, special fields and translation; the second includes bilingual skill of translating, intercultural communicative skill, and proficiency of English and Chinese; the third is concerned with skills of management, software, translating tools, communication, and the ability of working under pressure and assessing and editing translated work; the last one involves professional beliefs, ethnics, conduct and professional development. 
Table 3 Summary of exploratory factor analysis of PC scale of student translators

\begin{tabular}{|c|c|c|c|c|c|c|}
\hline \multirow{2}{*}{ Common Factor } & \multirow{2}{*}{ Item } & \multirow{2}{*}{ Variance (\%) } & \multicolumn{4}{|c|}{ Factor } \\
\hline & & & 1 & 2 & 3 & 4 \\
\hline \multirow{3}{*}{$\begin{array}{l}\text { Professional } \\
\text { Knowledge (PK) }\end{array}$} & s3 & 22.343 & .774 & & & \\
\hline & $\mathrm{s} 2$ & & .744 & & & \\
\hline & s1 & & .618 & & & \\
\hline \multirow[t]{4}{*}{ Core Skills (CK) } & s7 & 14.952 & & .845 & & \\
\hline & s6 & & & .802 & & \\
\hline & s8 & & & .787 & & \\
\hline & s5 & & & .717 & & \\
\hline \multirow{7}{*}{$\begin{array}{l}\text { Related } \\
\text { (RK) }\end{array}$} & s16 & 14.911 & & & .749 & \\
\hline & s15 & & & & .742 & \\
\hline & s14 & & & & .698 & \\
\hline & s17 & & & & .618 & \\
\hline & s12 & & & & .570 & \\
\hline & s9 & & & & .500 & \\
\hline & s10 & & & & .444 & \\
\hline \multirow{9}{*}{$\begin{array}{l}\text { Professional } \\
\text { Attitudes (PA) }\end{array}$} & s23 & 8.883 & & & & .895 \\
\hline & s25 & & & & & .864 \\
\hline & s24 & & & & & .821 \\
\hline & s22 & & & & & .768 \\
\hline & s18 & & & & & .702 \\
\hline & s19 & & & & & .684 \\
\hline & s26 & & & & & .635 \\
\hline & s21 & & & & & .597 \\
\hline & s20 & & & & & .587 \\
\hline Eigenvalue & & & 5.139 & 3.439 & 3.430 & 2.043 \\
\hline
\end{tabular}

Structure equation modeling (SEM) methods were used to check the validity of the questionnaire. The goodness-of-fit of the models was evaluated using absolute and relative indices. The absolute goodness-of-fit calculated was the Root Mean Square Error of Approximation (RMSEA). Values smaller than 0.08 for RMSEA are indicative of an acceptable fit, and values greater than 0.1 should lead to model rejection. Besides, as recommended other relative goodness-of-fit indices are also computed. They are (a) the Comparative Fit Index (CFI), a population measure of model misspecification that is particularly recommended for model comparison purposes; and (b) the Tucker-Lewis Index (TLI), which is a relative measure of covariation explained by the model that is specifically developed to assess factor models. For both relative fit indices, as a rule of thumb, values greater than .90 are considered as indicating a good fit. The details of goodness-of-fit indices show that RMSEA is 0.076, GFI is 0.948, AGFI is 0.913, TLI is 0.905 and CFI is 0.907. It can be found that the construct validity of the instrument is quite satisfactory.

\section{Descriptive Statistics of the PC of Translator Training}

To answer the first research question, the descriptive statistics of the perceptions of the students of seven MTI programs need to be presented. The mean of PC is 3.144 and it reflects that the status quo of PC is slightly above the average and needs to be improved. Comparatively speaking the level of PA (mean=4.030) is better than that of CK (mean=3.248), RK (mean=3.441) and PK (mean=2.795). Obviously, the amount of PK acquired by MTI students is below the average. A 
close look at the mean of each particular item revealed that the mean of Item s1, s2 and s3 is only $3.012,2.698$ and 2.676 respectively. $74.3 \%$ subjects either disagree, strongly disagree or not sure about whether their knowledge of translation is sufficient for professional work (s1). $77.7 \%$ subjects are not confident with their knowledge of special fields (eg law, economics) (s2). Only 13.5\% subjects think they have acquired sufficient knowledge of technical terms for translation (s3).

\section{Independent Sample t Test and ANOVA}

To answer the second research question the independent sample $\mathrm{t}$ test and ANOVA were conducted and the results are in Table 4 and Table 5.

Table 4 Summary of independent sample T test

\begin{tabular}{|c|c|c|c|c|c|c|c|}
\hline Variable & Group & Total & Mean & SD & Mean of Standard Error & $\mathrm{T}$ & $\mathrm{P}$ \\
\hline \multirow[t]{2}{*}{ Gender } & Female & 506 & 81.58 & 9.801 & .436 & \multirow[b]{2}{*}{-.663} & \multirow{2}{*}{.509} \\
\hline & Male & 96 & 82.53 & 13.378 & 1.365 & & \\
\hline \multirow[t]{2}{*}{ Duration of Program } & $2.5 \mathrm{yrs}$ & 194 & 81.48 & 11.528 & .828 & \multirow{2}{*}{-.401} & \multirow{2}{*}{.688} \\
\hline & 3 yrs & 408 & 81.85 & 9.904 & .490 & & \\
\hline \multirow[t]{2}{*}{ Major of First Degree } & Non-English & 74 & 53.82 & 8.415 & .978 & \multirow[t]{2}{*}{-.779} & \multirow{2}{*}{.436} \\
\hline & English & 528 & 54.62 & 8.237 & .358 & & \\
\hline \multirow[t]{2}{*}{ Part-time Student } & No & 471 & 81.49 & 10.567 & .487 & \multirow[t]{2}{*}{-1.050} & \multirow[t]{2}{*}{.294} \\
\hline & Yes & 131 & 82.58 & 9.994 & .873 & & \\
\hline \multirow{2}{*}{$\begin{array}{l}\text { Authentic Translation } \\
\text { Practice }\end{array}$} & No & 326 & 79.38 & 9.961 & .552 & \multirow[t]{2}{*}{-6.196} & \multirow[t]{2}{*}{.000} \\
\hline & Yes & 276 & 84.51 & 10.339 & .622 & & \\
\hline \multirow[t]{2}{*}{ Certified Translator } & No & 465 & 81.19 & 10.838 & .503 & \multirow[t]{2}{*}{-2.322} & \multirow[t]{2}{*}{.021} \\
\hline & Yes & 137 & 83.55 & 8.784 & .750 & & \\
\hline \multirow[t]{2}{*}{ Type of Institution } & Comprehensive & 275 & 81.71 & 10.461 & .631 & \multirow[t]{2}{*}{-.051} & \multirow[t]{2}{*}{.960} \\
\hline & Foreign Studies & 327 & 81.75 & 10.450 & .578 & & \\
\hline \multirow[t]{2}{*}{ Location of Institution } & West China & 270 & 81.90 & 9.287 & .565 & \multirow[t]{2}{*}{.370} & \multirow[t]{2}{*}{.712} \\
\hline & East China & 332 & 81.59 & 11.315 & .621 & & \\
\hline
\end{tabular}

Table 5. Summary of ANOVA analysis

\begin{tabular}{|c|c|c|c|c|c|c|c|c|c|}
\hline Variable & & $\begin{array}{c}\text { Sum of } \\
\text { Squares }\end{array}$ & df & $\begin{array}{l}\text { Mean of Sum } \\
\text { of Squares }\end{array}$ & F Test & Schefft & HSD & LSD & Tamhane \\
\hline \multirow{2}{*}{$\begin{array}{l}\text { HEI of First } \\
\text { Degree }\end{array}$} & Between & 291.098 & 2 & 145.549 & 1.335 & n.a. & & & \\
\hline & $\begin{array}{l}\text { Groups } \\
\text { Within Group }\end{array}$ & 65296.844 & 599 & & & & & & \\
\hline \multirow[t]{2}{*}{ Study Year } & $\begin{array}{l}\text { Between } \\
\text { Groups }\end{array}$ & 687.971 & 2 & 343.986 & $3.175^{*}$ & & $\mathrm{C}>\mathrm{A}$ & $\mathrm{C}>\mathrm{A}$ & \\
\hline & Within Group & 64899.970 & 599 & 108.347 & & & & & \\
\hline \multirow[t]{2}{*}{$\begin{array}{l}\text { English } \\
\text { Proficiency }\end{array}$} & $\begin{array}{l}\text { Between } \\
\text { Groups }\end{array}$ & 34.332 & 2 & 34.332 & .314 & n.a. & & & \\
\hline & Within Group & 65553.610 & 599 & 109.256 & & & & & \\
\hline \multirow{2}{*}{$\begin{array}{l}\text { Knowledge } \\
\text { of } \\
\text { Profession }\end{array}$} & $\begin{array}{l}\text { Between } \\
\text { Groups }\end{array}$ & 5925.708 & 2 & 2962.85 & $\begin{array}{l}29.747 * \\
*\end{array}$ & $\mathrm{~B}>\mathrm{A}$ & $B>A$ & $B>A$ & \\
\hline & Within Group & 59662.234 & 599 & 4 & & $\mathrm{C}>\mathrm{A}$ & $\mathrm{C}>\mathrm{A}$ & $\mathrm{C}>\mathrm{A}$ & \\
\hline \multirow[t]{2}{*}{$\begin{array}{l}\text { Satisfaction } \\
\text { of Program }\end{array}$} & $\begin{array}{l}\text { Between } \\
\text { Groups }\end{array}$ & 4511.771 & 2 & 2255.88 & & & & & $\mathrm{C}>\mathrm{A}$ \\
\hline & Within Group & 61076.171 & 599 & 5 & $\begin{array}{l}22.124 * \\
*\end{array}$ & & & & $\mathrm{C}>\mathrm{B}$ \\
\hline
\end{tabular}

Note: $\mathrm{n} . \mathrm{a} *$ means $\mathrm{p}>0.05 ; * *$ means $\mathrm{p}<0.001$

It shows that there is no statistically significant difference in gender, duration of program, major of first degree, type of study, type of institution, and location of institution in terms of students' perceptions of their PC. In other words the perceptions of the students of the PC are quite similar regardless of their educational background, and where and what types and how long the MTI program is. However, the fact that whether they have authentic translation practicum and are 
already certified translators does play a critical role in their PC.

The result of ANOVA analysis reveals that there is no significant difference between students graduated from different types of universities while the difference between Year Three and the other two groups (Year One and Year Two) does exist $(\mathrm{p}=0.043<0.05)$. This may attribute to the amount of time and efforts that Year Three students have put on their program. Though English proficiency does not seem to greatly influence students' PC, their familiarities of the profession and satisfaction with MTI programs do significantly affect their PC. This may shed some light on the importance of providing more knowledge of profession and a better learning experience to MTI students.

\section{Conclusion}

The study presented here applied the theory of competence and surveyed the PC of MTI students in China. The findings include:

-The PC of MTI students of China consists of four factors, namely professional knowledge, core skills, related skills and professional attitudes.

-Of the four factors MTI students' PA is quite satisfactory but their lack of PK is in an acute situation and deserves more attention in future study. It may bring some changes to the curriculum of current MTI programs.

-The perceptions of the students of their PC are quite similar regardless of where and what types and how long the MTI program is, but the experience of authentic translation practicum and being certified do significantly influence their level of PC.

-The educational background of MTI students and their proficiency of English do not seem to influence their PC but the amount of time and efforts they put on study, their understanding of profession, and satisfaction of the learning experience do considerably affect their PC.

\section{Acknowledgments}

The research was financially supported by the research funding of Northwest University (No. JX17009) and Shaanxi Educational Research (No. SGH140582).

\section{References}

[1] H. Wang, L. Zhang, BTI and MTI education in China, Shanghai Journal of Translators. 2(2016) 13-17+94.

[2] W. Zhong, The reflections on MTI education and its road ahead, Chinese Translators Journal. 3(2017) 7-9.

[3] L. Gao, Y. Cui, An empirical study of the professional preparation environment of MTI students, Foreign Languages in China. 1(2016) 56-67.

[4] D. McClelland, Testing for competence rather than "intelligence", American Psychologist. 1(1973) 1-14.

[5] J. S. Stark, A conceptual framework for the study of pre-service professional programs in colleges and universities, The Journal of Higher Education. 3(1986) 231-258.

[6] J. Zhang, A Theoretical Study to Developing a Competence-based Disaster Nursing Curriculum, PhD Dissertation, The Second Military Medical University.

[7] Y. Zhou, D. He, The characteristics of professional translators' competence and translator education, Chinese Translators Journal. 6(2013) 65-67.

[8] J. Miao, S. Wang, The tendency of translation profession and its inspiration for MTI education, Foreign Languages and Their Teaching. 3(2010) 63-67. 